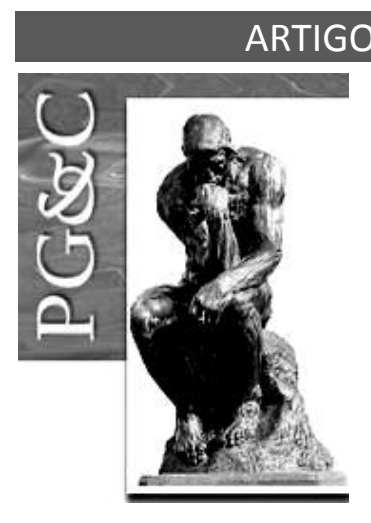

\title{
SELEÇÃO DE TIPOS DE FONTES DE INFORMAÇÃO
}

\author{
Claudia Carmem Baggio \\ Mestranda em Ciência da Informação pela Universidade Federal \\ de Santa Catarina, Brasil. \\ E-mail: ccbaggio@gmail.com \\ Heloisa Costa \\ Mestranda em Ciência da Informação pela Universidade Federal \\ de Santa Catarina, Brasil. \\ E-mail: helocosta7@hotmail.com \\ Ursula Blattmann \\ Doutora em Engenharia de Produção pela Universidade Federal \\ de Santa Catarina, Brasil. Professora da Universidade Federal \\ de Santa Catarina, Brasil. \\ E-mail: ublattmann@gmail.com
}

\section{Resumo}

Fontes de informação são parte integral dos serviços de informação prestados aos usuários. Identificálas é o primeiro passo para buscar e recuperar informação pontual. Este artigo apresenta o conceito de fontes de informação e sua classificação, bem como os possíveis instrumentos para localização de fontes de informações, apresentando os conceitos, os tipos e os exemplos de repositórios, catálogos, bibliografias, portais, diretórios e bases de dados.

Palavras-chave: Fontes de Informação. Repositórios. Catálogos. Recuperação da Informação.

\section{SELECTION OF TYPES OF INFORMATION RESOURCES}

\begin{abstract}
Information sources are an integral part of the information services provided to users. Identifying them is the first step to search and retrieve specific information. This article introduces the concept of information sources and their classification, as well as the possible tools for locating information sources, presenting the concepts, types and examples of repositories, catalogs, bibliographies, portals, directories and databases.
\end{abstract}

Keywords: Sources of Information. Repositories. Catalog. Information Retrieval.

\section{INTRODUÇÃO}

A necessidade de obter informação facilmente esbarra na quantidade de informação disponível, tanto na web como em materiais impressos. O usuário quando busca informação encontra dificuldades na seleção e recuperação, devido à quantidade existente e à velocidade com que as informações se modificam.

A informação pontual é o elemento pelo qual o usuário inicia sua busca nas diversas fontes existentes. Para Le Coadic (1996, p. 5), a informação pode ser "um conhecimento inscrito sob a forma escrita, oral ou audiovisual. Ela comporta um elemento de sentido e é transmitida a um ser consciente por meio de uma mensagem inscrita". Assim, os itens

Perspectivas em Gestão \& Conhecimento, João Pessoa, v. 6, n. 2, p. 32-47, jul./dez. 2016. http://periodicos.ufpb.br/ojs2/index.php/pgc. ISSN: 2236-417X. Publicação sob Licença (cc) EY-NC-ND 
informacionais podem estar disponíveis de diversas formas e por meio de muitos canais de informação, incluindo a internet, que disponibiliza materiais advindos de vários locais por meio das fontes de informação.

Neste cenário, as fontes de informação aparecem como uma ferramenta que auxilia na recuperação de informações para usuários inseridos em diferentes contextos.

"Uma fonte de informação é qualquer recurso que responda a uma demanda de informação por parte dos usuários, incluindo produtos e serviços de informação, pessoas ou rede de pessoas, programas de computador, etc.". (BIREME, 2001, p. 7).

As fontes de informação são geralmente utilizadas por pesquisadores, acadêmicos (docentes e discentes), e, usuários comuns. No entanto, com a grande quantidade de informação disponível é preciso saber onde buscar as fontes de informação que atendam as necessidades de informação de todos esses usuários. A Internet se constitui em um canal que disponibiliza inúmeras fontes de informação, no entanto, nem sempre é uma informação de fácil recuperação e de fontes confiáveis.

As fontes de informação podem ser classificadas em fontes primárias, secundárias e terciárias. De acordo com Cunha (2001), as fontes primárias "[...] são fatos vindos diretamente das fontes e não adulterados [...]. É uma informação que não pode ser mudada, alterada ou disfarçada por opiniões ou seleções". De acordo com Pinheiro (2006, p. 2), as fontes ou recursos de informação em meio eletrônico primários "correspondem à 'literatura primária' e são aqueles que se apresentam e disseminados exatamente na forma com que são produzidos por seus autores". Como exemplo tem-se: congressos e conferências, legislação, nomes e marcas comerciais, normas técnicas, patentes, periódicos, projetos e pesquisa em andamento, relatórios técnicos, teses e dissertações e traduções.

As fontes secundárias "contêm, informações sobre documentos primários e são arranjados segundo um plano definitivo; são, na verdade, os organizadores dos documentos primários e guiam o leitor para eles [...]" (CUNHA, 2001, p. ix). Podem ser: livros, manuais, internet, museus, herbários, arquivos e coleções científicas, prêmios e honrarias, redação técnica e metodologia científica, siglas e abreviaturas, tabelas, unidades, medidas e estatística, bases de dados e bancos de dados, bibliografias e índices, biografias, catálogos de bibliotecas, centros de pesquisa e laboratórios, dicionários e enciclopédias, dicionários bilíngues e multilíngues, feiras e exposições, filmes e vídeos, fontes históricas.

$\mathrm{E}$, as fontes terciárias ajudam "o leitor na pesquisa de fontes primárias e secundárias, [...] [e atuam como] sinalizadores de localização ou indicadores sobre os documentos primários ou secundários, além de informação factual [...]" (CUNHA, 2001, p. ix), que podem ser: bibliografia de bibliografia, bibliografia e centros de informação, diretórios, financiamento e fomento à pesquisa, guias bibliográficos, revisões de literatura.

Nessa perspectiva, este artigo tem a finalidade de apresentar instrumentos para localização e seleção de fontes de informação para auxiliar pesquisadores, acadêmicos e aos profissionais da informação no acesso e uso da informação.

\subsection{Procedimentos Metodológicos}

Este artigo foi elaborado utilizando as técnicas da pesquisa exploratória e bibliográfica, pois foi realizado levantamento na literatura a respeito das fontes de informação aqui apresentadas.

No entendimento de Cervo e Bervian (2002, p. 69), "os estudos exploratórios não elaboram hipóteses a serem testadas no trabalho, restringindo-se a definir objetivos e buscar mais informações sobre determinado assunto de estudo".

As fontes de estudos para elaboração do artigo são vastas: livros, artigos consagrados e publicados permitiram a utilização da pesquisa bibliográfica que para Andrade (2003, p. 126),

Perspectivas em Gestão \& Conhecimento, João Pessoa, v. 6, n. 2, p. 32-47, jul./dez. 2016 
"[...] tanto pode ser um trabalho independente como se constituir no passo inicial de outra pesquisa".

Na compreensão de Gil (2002, p. 44), a pesquisa bibliográfica "é desenvolvida com base em material já elaborado, constituído principalmente de livros e artigos científicos [...]. Boa parte dos estudos exploratórios pode ser definida como pesquisa bibliográfica".

Nesse sentido, apresentam-se nas próximas seções as fontes de informação e os instrumentos para localização das fontes.

\section{FONTES DE INFORMAÇÃO}

Entender como se dividem as fontes de informação auxilia na busca e recuperação da informação, pois de acordo com o tipo de informação pode ser utilizada uma fonte específica.

Nessa perspectiva, é necessário conhecer os tipos de fontes de informação e suas características para compreender como se dividem e se classificam e se situam em cada canal de informação.

De acordo com Grogan (1970 apud CUNHA, 2001, p. ix), os documentos ou fontes de informação podem ser divididos em três categorias:

a) documentos primários: contêm, principalmente, novas informações ou novas interpretações de ideias e/ou fatos acontecidos; alguns podem ter o aspecto de registro de observações (como, por exemplo, os relatórios de expedições científicas) ou podem ser descritivos (como a literatura comercial);

b) documentos secundários: contêm informações sobre documentos primários e são arranjados segundo um plano definitivo; são, na verdade, os organizadores dos documentos primários e guiam o leitor para eles;

c) documentos terciários: têm como função principal ajudar o leitor na pesquisa de fontes primárias e secundárias, sendo que, na maioria, não trazem nenhum conhecimento ou assunto como um todo, isto é, são sinalizadores de localização ou indicadores sobre os documentos primários ou secundários, além de informação factual; este livro é um exemplo de documento terciário.

Alguns exemplos de fontes primárias podem ser: congressos e conferências, legislação, nomes e marcas comerciais, normas técnicas, patentes, periódicos, projetos e pesquisa em andamento, relatórios técnicos, teses e dissertações e traduções. As secundárias: livros, manuais, internet, museus, herbários, arquivos e coleções científicas, prêmios e honrarias, redação técnica e metodologia científica, siglas e abreviaturas, tabelas, unidades, medidas e estatística, bases de dados e bancos de dados, bibliografias e índices, biografias, catálogos de bibliotecas, centros de pesquisa e laboratórios, dicionários e enciclopédias, dicionários bilíngues e multilíngues, feiras e exposições, filmes e vídeos, fontes históricas. E, as terciárias: bibliografia de bibliografia, bibliografia e centros de informação, diretórios, financiamento e fomento à pesquisa, guias bibliográficos, revisões de literatura. (CUNHA, 2001).

Hjørland, Andersen e Søndergaard (2005, p. 13, tradução nossa) acrescentam a esses três divisões, outras duas, conforme seguem:

- Literatura Popular: Exportação do conhecimento produzido em um domínio para o público em geral, outros domínios, ou estudantes. Exemplos: livros didáticos, revistas, jornais (por exemplo, o jornalismo científico), livros populares (incluindo enciclopédias), particularidades, ficção científica, mídia de massa, apresentações multimídia, etc. 
- Informações ao fundo: as informações sobre ferramentas (incluindo computadores e software), a evolução do mercado de trabalho, na disciplina = domínio, etc., desde que tais informações não podem ser vistos como parte da produção do conhecimento comum dos domínios. Exemplos: documentos biográficos, diretórios, calendários de conferências, as listas de arquivos, diretório de subvenções, bolsas de estudo, etc., anuários (relatórios anuais), newsletters, homepages pessoais.

O aumento de informação [...] apresenta diversos fatores, que na visão de Cunha (2001) se relacionam: ao acúmulo de novos conhecimentos, principalmente após a Segunda Guerra Mundial; a diversificação de áreas de conhecimentos; [...] o surgimento de novas disciplinas científicas; o aumento do número de usuários e a diversificação de seus interesses; os fenômenos de repetição e duplicação de pesquisas; interesses extracientíficos, entre outras razões.

\subsection{Instrumentos para localização de Fontes de Informação}

Para Campello, Cendón e Kremer (2000), as tecnologias de informação e comunicação causaram mudanças nos canais formais e informais, que se modificaram, ampliaram e diversificaram, tornando a transmissão da informação mais rápida e eficiente. Para as autoras, a internet permitiu a explosão da literatura, por meio de novos formatos e canais de comunicação, eliminando, inclusive, as barreiras geográficas. Contudo, é necessário garantir acesso às inúmeras publicações disponíveis na web.

A partir do entendimento de que as fontes de informação correspondem à origem da informação, existe uma classificação para as diversas origens cujos critérios são o seu conteúdo, propósito ou função (PINHEIRO, 2006). Para a autora supracitada, as fontes ou recursos informacionais eletrônicos (aqueles disponíveis na internet) abrangem todos os três tipos de fontes: primárias, secundárias e terciárias.

Dessa forma, para acessar informações relevantes são necessários conhecimentos e habilidades que permitam identificar e selecionar as informações que atendam as necessidades de cada usuário.

Algumas fontes de informação atuam como instrumentos para localização das fontes. Podem ser os repositórios, catálogos, bibliografias, portais e diretórios, entre outros. Estes instrumentos funcionam como mecanismos contentores de informação que levam às fontes de informação. Neste artigo são descritos aspectos que apresentam os repositórios, catálogos, bibliografias, portais e diretórios, conceituando-os e citando exemplos práticos de cada um desses instrumentos.

\subsection{Repositórios}

Os repositórios digitais surgiram a partir do movimento de acesso aberto como um novo canal de informação de forma a aumentar a visibilidade da produção científica. Existem muitas definições para repositórios; no entanto, no contexto da ciência da informação Guédon (2009) aponta que existe uma falta de definição quanto a sua natureza, mas destaca que isso faz parte do processo da escola de pensamento da construção social da tecnologia.

O desenvolvimento de repositórios institucionais emergiu em 2002, como uma nova estratégia que permitiu às universidades assumirem o papel de editoras, modernizando os processos de publicação e divulgando a produção acadêmica em conteúdo digital (LYNCH, 2003). Servidores ou repositórios de documentos, são instrumentos para a implementação de autoarquivamento, de acesso aberto. Esses bancos de dados são operados por universidades

Perspectivas em Gestão \& Conhecimento, João Pessoa, v. 6, n. 2, p. 32-47, jul./dez. 2016 
ou organismos de investigação. Tanto a colocação de documentos pelos autores, como o acesso do usuário, são gratuitos.

Sarmento et al. $(2005$, p. 3) afirmam que os "repositórios são coleções digitais que armazenam, preservam e tornam disponível a produção intelectual de uma ou mais universidades, sem qualquer custo para o produtor e consumidor da informação".

Camargo e Vidotti, (2009, p. 55) complementam, afirmando que "os repositórios digitais possibilitam o controle, a preservação e a visibilidade da produção científica, minimizando custos de publicações e permitindo o acesso irrestrito de outras comunidades universitárias e de pesquisa e da sociedade em geral".

O dicionário Michaelis (2015) conceitua repositório, entre outras definições, como: soma de conhecimentos. Segundo o Instituto Brasileiro de Informação em Ciência e Tecnologia (2015), repositórios digitais são bases de dados online que reúnem de maneira organizada a produção científica de uma instituição ou área temática. Considerando os exemplos citados, pode-se entender os repositórios como um lugar onde se armazenam conteúdos diversos, categorizados e indexados, para serem acessados pelos usuários.

Para Murakami e Fausto (2013, p. 187), "hoje se verifica a existência ampliada de repositórios mundialmente, em especial em países que buscam promover a visibilidade e o acesso facilitado de sua produção científica".

No universo científico e acadêmico é extremamente crucial a criação e disponibilização de recursos que cedam informação/documentação de qualidade e em tempo útil, de modo a incrementar e fomentar o espírito crítico e o rigor acadêmico em todo o processo de aprendizagem da comunidade. (RODRIGUES, 2011, p. 2).

Na visão de Murakami e Fausto (2013), os repositórios digitais representam a rápida evolução da comunicação científica no ambiente virtual. Essa evolução partiu de iniciativas como a Iniciativa Arquivos Abertos (Open Archive Initiative - OAl) e o Movimento de Acesso Aberto (Open Access Movement - OAM), "visando promover modelos eficientes de armazenamento, disseminação, visibilidade e acesso aos conteúdos científicos". (MURAKAMI; FAUSTO, 2013, p. 186).

Repositórios são definidos como um "sistema de informação responsável por gerir e armazenar material digital" (FERREIRA, 2006, p. 71). Os repositórios podem ser do tipo institucional, compreendendo a produção científica de uma instituição; temáticos, abrangendo a produção científica de uma determinada área do conhecimento; governamentais, registrando documentos de órgãos governamentais; ou agregador, caracterizando um repositório que reúne registros de outros repositórios (KURAMOTO, 2012).

Para Costa (2008, p. 225), os repositórios representam uma espécie de revolução de disseminação da pesquisa, pois o

[...] autoarquivamento em repositórios institucionais ou temáticos de trabalhos já publicados ou aceitos para publicação em periódicos ou outros veículos de comunicação. Isto é, de trabalhos já avaliados por pares. [...] maximiza o acesso, a visibilidade e o progresso da pesquisa. Não se trata de substituir nenhum outro estágio do processo de comunicação, principalmente, o estágio da publicação formal, mas de uma instância eficaz de disseminação ampla e irrestrita, livre de barreiras de preço e de permissão de uso. Desse modo, os repositórios devem conter uma cópia de todo trabalho publicado ou aceito para publicação em periódicos, livros ou outro veículo, em ambiente interoperável e aberto. 
Os repositórios são classificados em temáticos (lidam com a produção científica de uma determinada área, sem limites institucionais), institucionais (lidam com a produção científica de uma determinada instituição) e de teses e dissertações (INSTITUTO BRASILEIRO DE INFORMAÇÃO EM CIÊNCIA E TECNOLOGIA, 2015).

"Os repositórios temáticos comportam vários tipos de documentos, inclusive periódicos científicos". (GARRIDO; RODRIGUES, 2010, p. 61). Entre os exemplos de repositórios temáticos na área da ciência da informação: EPrints in Library and Information Science (E-LIS) (http://eprints.rclis.org/), que é um repositório digital internacional de Biblioteconomia e Ciência da Informação. Possui uma equipe de editores voluntários e suporte para 22 idiomas. O desenvolvimento de uma rede internacional tem sido estimulado pela extensão do conceito Open Access e funciona por meio da difusão de material dentro da área. Outro exemplo é o arXiv.org (http://arxiv.org/), que é um serviço de e-print ${ }^{1}$ nos campos da física, matemática, ciência da computação, biologia quantitativa, finanças quantitativas e estatísticas. (E-LIS, 2015; ARXIV.ORG, 2015; INSTITUTO BRASILEIRO DE INFORMAÇÃO EM CIÊNCIA E TECNOLOGIA, 2012).

Gomes e Rosa (2010) apontam os repositórios institucionais como "[...] uma das estratégias mais eficazes de melhoria das condições de disponibilidade e facilitação do acesso à produção intelectual, acadêmica e científica dos centros produtores do conhecimento, como as universidades e centros de investigação" (GOMES; ROSA, 2010, p. 7).

Em relação aos repositórios institucionais, o Instituto Brasileiro de Informação em Ciência e Tecnologia $(2012$, p. 7) pontua que eles "constituem de fato inovação no sistema de comunicação da ciência e no modo como a informação - aquela que alimenta e resulta das atividades acadêmicas e científicas - é gerenciada". Um exemplo de repositório institucional é o ePrints Soton (http://eprints.soton.ac.uk/), que é o repositório de pesquisa da Universidade de Southampton (na Inglaterra). Contém artigos de revistas, livros, teses de doutorado, documentos de conferências, dados, relatórios, documentos de trabalho, exposições de arte e muito mais. Sempre que possível, artigos de periódicos e anais de eventos são enviados para ePrints, disponibilizados em acesso aberto no intuito de disponibilizar a pesquisa para muito mais pessoas. (EPRINTS SOTON, 2015).

Os repositórios de teses e dissertações têm por finalidade reunir os trabalhos de pósgraduação (mestrado e doutorado) defendidos em diversas universidades. Este acesso permite que se possa obter conhecimento sobre o que está sendo pesquisado e desenvolvido na academia, fruto de pesquisas em atividades comerciais e industriais. No Brasil, existem diversos repositórios de teses e dissertações, sendo dois a destacar: 1) o Portal de Teses da CAPES (http://capesdw.capes.gov.br), que é o sistema online oficial do governo brasileiro para depósito de teses e dissertações brasileiras, vinculado ao Ministério da Educação (MEC); e, 2) o Banco de Teses do IBICT (http://bdtd.ibict.br/pt), trata-se de um mecanismo de busca que integra todas as Bibliotecas Digitais de Teses e Dissertações (BDTD) das universidades brasileiras que utilizam o sistema BDTD do IBICT. (UFSCar, 2011).

No Brasil foi criado o Projeto de Lei n.o 1120/2007 que pretendeu assegurar a construção de repositórios para disseminar, via internet e de forma livre, a produção técnicocientífica brasileira, entre outras importantes determinações, visando à criação de mais repositórios e, desta forma, aumentando a visibilidade científica brasileira (MONTEIRO;

\footnotetext{
${ }^{1}$ Eprints são os textos digitais de artigos de pesquisa revisados por pares, antes e depois da avaliação. Antes de avaliação e publicação, o projeto é chamado de "pré-impressão". Quando o projeto final é aceito é chamado de "postprint." Eprints incluem tanto preprints e postprints (bem como quaisquer rascunhos significativos no meio, e nenhuma atualização pós-publicação). Os pesquisadores são incentivados a autoarquivar todos eles. Todas as versões devem conter links para a versão oficial do registro do editor (EPRINTS, 2015).
}

Perspectivas em Gestão \& Conhecimento, João Pessoa, v. 6, n. 2, p. 32-47, jul./dez. 2016 
BRASCHER, 2007). Porém, encontra-se arquivado desde janeiro de 2011 e sem previsão de retornar ao fluxo de tramitação.

O IBICT incentiva, instrumentaliza e capacita as universidades brasileiras na adoção de repositórios, dando assim visibilidade à sua produção intelectual, recomendando a adoção do DSpace ou do E-prints, plataformas desenvolvidas pelo Massachusetts Institute of Technology (MIT) e University of Southampton, respectivamente (COSTA, 2008).

\title{
2.3 Catálogos
}

Os catálogos surgiram para armazenar e registrar as informações sobre os documentos existentes em um acervo, todavia, sua função passou por uma metamorfose em decorrência do aumento de materiais impressos, inclusive no que tange a ampliação da produção de livros e a consequente necessidade de organização desse material para posterior recuperação. Por isso, ocorreu uma mudança de foco no uso dos catálogos, de simples função de depósito para uma ferramenta arrojada de uso da recuperação de informações (MARTINHO; FUJITA, 2011).

Mey $(1995$, p. 12) comenta sobre o surgimento dos catálogos ao dizer que:

\begin{abstract}
Datam de 1300 a.C. os tabletes com as primeiras informações bibliográficas de descrição física, encontrados em escavações hititas. Esses tabletes identificavam o número do tablete em uma série, o título e, muitas vezes, o escriba. As informações são encontradas outra vez nas escavações da biblioteca do rei assírio, Assurbanipal, em Nívive, datando de 650 a.C. Encontram-se cerca de 20 mil tabletes, que registravam o título, o número do tablete ou volume, as primeiras palavras do tablete seguinte, o nome do possuidor original, o nome do escriba e um selo, indicando trata-se de propriedade real. Presume-se haver, nesta época, um embrião do catálogo. Existiu, certamente, um catálogo, inscrito nas paredes de um templo no Egito, mas datado dos séculos III e II a.C.
\end{abstract}

$\mathrm{Na}$ atualidade, a definição de catálogo parou de estar ligada exclusivamente ao livro para ser compreendido também como um meio de comunicação. Mey $(1995$, p. 9) conceitua catálogo como: "[...] um canal de comunicação estruturado, que veicula mensagens contidas nos itens, e sobre os itens, de um ou vários acervos, apresentando-se sob forma codificada e organizada, agrupadas por semelhanças, aos usuários desse(s) acervo(s)".

A área que estuda os catálogos é entendida como catalogação, que na visão de Mey $(1995$, p. 5) é o "[...] estudo, preparação e organização de mensagens codificadas, com base em itens existentes ou passíveis de inclusão em um ou vários acervos, de forma a permitir interseção entre as mensagens contidas nos itens e as mensagens internas dos usuários".

Segundo exemplifica o Dicionário Brasileiro de Terminologia Arquivística (1996, p. 45) "catálogo é um instrumento de pesquisa em que a descrição exaustiva ou parcial de um fundo ou de uma ou mais de suas subdivisões toma por unidade a peça documental, respeitada ou não a ordem de classificação".

"Catálogo é um meio de comunicação, que veicula mensagens sobre os registros do conhecimento, de um ou vários acervos, [...] reunindo os registros do conhecimento por semelhanças, para os usuários desse acervo". (MEY; SILVEIRA, 2009, p. 12).

"O catálogo tem uma função essencial como meio de comunicação, conduzindo o usuário à informação almejada com o menor número de falhas e a maior quantidade de possibilidades possíveis". (PAIVA, 2011, p. 3).

As funções dos catálogos são: encontrar, identificar, selecionar e obter recursos bibliográficos. Indicar obras existentes, por autor ou qualquer outro responsável pela publicação (tradutor, ilustrador, etc.); indicar nomes das instituições ou entidades das quais a 
biblioteca possua obras; dispor ordenadamente as entradas de autor para possibilitar a identificação das obras pelo título; possibilitar a recuperação das obras pelo título; indicar as obras existentes sobre determinado assunto; através de remissivas, orientar o leitor de uma entrada para outra que foi estabelecida; indicar o conteúdo e descrever dados que permitam a identificação e recuperação das obras na estante. (IFLA MEETINGS OF EXPERTS ON AN INTERNATIONAL CATALOGUING CODE, 2009).

Cataloguing Code (2009), os catálogos têm a função de encontrar, identificar, selecionar e obter recursos bibliográficos e facilitar a navegação dentro ou fora dele.

Um exemplo de catálogo é o da biblioteca do IBICT (http://www.ibict.br/informacaopara-ciencia-tecnologia-e-inovacao/2biblioteca-do-ibict). A Biblioteca do IBICT possui um acervo especializado em biblioteconomia, ciência da informação e áreas correlatas, formado por monografias, publicações seriadas, anais de eventos, relatórios, memória técnica, documentos eletrônicos, multimeios e obras de referência. Oferece os seguintes produtos e serviços de informação: catálogo online do acervo da Biblioteca, levantamento bibliográfico, pesquisa no Portal de periódicos da Capes, catalogação na fonte das publicações do IBICT, normalização de referências dos periódicos, serviços de COMUT e reprografia, entre outros serviços de informação (INSTITUTO BRASILEIRO DE INFORMAÇÃO EM CIÊNCIA E TECNOLOGIA, 2015).

Com o desenvolvimento de tecnologias utilizadas no âmbito das unidades de informação teve-se o inicio da informatização dos catálogos. O surgimento de tecnologias para uso nos serviços desenvolvidos nas unidades de informação cresce de forma rápida, principalmente, na produção dos métodos de representação descritiva processando desta forma mais rápido os caminhos de pesquisa dos usuários e a conseguinte facilitação da recuperação de informações presentes nos catálogos online.

Uma mudança perceptível está no fato dos catálogos, que por um grande período foram construídos para uma comunidade local, passaram a ser disponibilizados na web em formato on-line, tornando-se disposto para acesso do público em geral (FUJITA, 2009).

No entendimento de Pozzi (2011),

As instituições sejam elas universidades, escolas, empresas entre outras, devem visualizar nos catálogos uma ferramenta confiável de armazenagem, busca e recuperação de informação. Pelas atividades de tratamento documentário, a comunidade usuária mediante uso do catálogo online pode recuperar o que necessita, a qualquer tempo e independente da localização geográfica, sendo o fato possível através da conexão com a web. Assim, as informações documentárias podem ser acessadas nos catálogos por vários pontos de acesso, podendo variar a busca de um item específico pelas inúmeras formas de abordagens do mesmo documento, sendo em relação à autoria, ao assunto, ao tipo de documento, a língua, entre outros.

De acordo com Oliveira (2008, p. 3):

Os catálogos online tornam possível a utilização de vários dos recursos, ocorrendo grande dinamicidade no uso dos sistemas e no acesso às informações, possibilitando o acesso de um item no mesmo momento por uma infinidade de usuários. Funcionam como parte da biblioteca da realidade virtual e apresentam-se com estruturas de bibliotecas físicas.

Conceitualmente, o catálogo online não demonstra, na área da ciência da informação, grandes diferenças aos catálogos manuais. Podemos destacar como uma das grandes facilidades destes instrumentos a questão de poderem oferecer catálogos de modo coletivo,

Perspectivas em Gestão \& Conhecimento, João Pessoa, v. 6, n. 2, p. 32-47, jul./dez. 2016 
ou seja, que permitam recuperar elementos de várias unidades de informação e o mais importante sem o auxílio de bibliotecários de referência presentes em bibliotecas tradicionais. (SILVEIRA, 2003).

A internet propiciou o surgimento dos catálogos e acesso online, que são automatizados, sendo considerados instrumentos que realizam pesquisas bibliográficas por meio de materiais ligados a softwares que facilitam a recuperação da informação de um modo mais rápido e eficiente pelos usuários.

\title{
2.4 Bibliografias
}

As bibliografias são um dos instrumentos para localização de fontes de informação mais utilizados no meio acadêmico, úteis para os pesquisadores individuais, bibliotecas e centros de documentação.

De acordo com o Dicionário Michaelis (2015), uma bibliografia é a ciência que trata da história, descrição e classificação dos livros, considerados como objetos físicos; inventário metódico dos livros; relação de obras recomendadas sobre determinado assunto; seção de uma publicação periódica destinada ao registro das publicações recentes, ou ainda, relação das obras consultadas pelo autor, geralmente no fim do trabalho a que serviram de subsídio. Neste trabalho, a bibliografia está relacionada a estes conceitos.

Para Cunha (2001, p. 36-37)

\begin{abstract}
a bibliografia é uma lista de referências bibliográficas relativas aos diversos tipos de fontes de informação sobre determinado assunto ou pessoa. Em geral, é organizado por ordem alfabética ou cronológica de autores. Em termos de cobertura, pode ser exaustiva ou seletiva, podendo trazer apenas a referência bibliográfica ou incluir anotações sobre o item analisado. Os índices, também denominados bibliografias correntes, em geral indexam novos livros e artigos de periódicos. Podem incluir Resumos (abstracts) e são publicados com frequência variada e de modo regular.
\end{abstract}

Pode-se citar alguns exemplos de bibliografias, tais como: Bailey Junior, Charles W. Scholarly electronic publishing bibliography: 2008 annual edition (http://www.digitalscholarship.org/sepb/sepb.html), que apresenta artigos em língua Inglesa, livros e outras fontes impressas e eletrônicas que são úteis para os acadêmicos. A bibliografia abrange uma vasta gama de tópicos, tais como: direitos autorais digitais, bibliotecas digitais, a preservação digital, repositórios digitais, e-books, e-revistas, contratos de licença, metadados e acesso aberto. A maioria das fontes relacionadas está entre os anos de 1990 e 2011. A bibliografia inclui links para as versões das obras e não inclui obras digitais de mídia (como arquivos MP3), editoriais, mensagens de e mail, cartas ao editor, artigos de jornais diários, slides de apresentação ou transcrições, ou postagens do blog (SCHOLARLY ELECTRONIC PUBLISHING BIBLIOGRAPHY, 2015; CUNHA, 2010).

Outro exemplo pode ser notado pela International Federation of Library Associations and Institutions (IFLA) (http://www.ifla.org/). "Digital libraries: resources and projects. Bibliografia de cunho internacional sobre coleções, periódicos, conferências, organizações e projetos de bibliotecas digitais". (INTERNATIONAL FEDERATION OF LIBRARY ASSOCIATIONS AND INSTITUTIONS, 2015; CUNHA, 2010).

\subsection{Portais}

Um portal é um site na internet que engloba conteúdos de outros sites, ou uma

Perspectivas em Gestão \& Conhecimento, João Pessoa, v. 6, n. 2, p. 32-47, jul./dez. 2016 
reunião de páginas, sites e websites da Internet, com a finalidade de promover o acesso facilitado a quem busca informação. No entender de Alves et al (2012), portais são ambientes estruturados que reúnem e/ou integram diversas fontes de informação.

De acordo com Santos (2011, p. 74), "os portais são fabulosos e ricos em divulgação e contextualização de informações especializadas em temas diversos". "[...] Não têm tanto impacto quanto as bases de dados e os diretórios, que implementam seus sistemas para que possam indexar de forma concreta as informações de algum tipo de suporte".

"Nos portais são divulgados links, que, na verdade, nada mais são do que a divulgação logística (hospedagem) da publicação em um portal de temática específica ou generalizado, de tema multidisciplinar, sem pretender realizar a indexação em si”. (SANTOS, 2011, p. 74).

Como exemplo de um portal pode-se citar o Portal de Divulgação Científica do SENAC/SP (http://www.sp.senac.br/), que é um portal que contém publicações científicas, práticas acadêmicas, pesquisa aplicada, eventos, base de dados, etc. Tem como objetivo promover a difusão do conhecimento técnico-científico e cultural, produzido em projetos científicos e acadêmicos da Instituição. O Centro Universitário Senac organiza revistas científicas, anais de eventos e relatórios técnico científicos para disseminar o conhecimento em suas áreas de atuação (SENAC-SP, 2015).

Outro exemplo bastante relevante, principalmente para o meio científico e tecnológico é o site do Conselho Nacional de Desenvolvimento Científico e Tecnológico (CNPq), que disponibiliza o Portal de popularização da Ciência - Por que popularizar? O portal se preocupa com a divulgação científica, disponibilizando as informações contidas em museus e centros de ciência, informações da Feira e Relatório de Ciências, da Memória CNPq, e das olimpíadas científicas. Este portal pode ser acessado por meio do website: (http://cnpq.br/popularizacaoda-ciencia). Além dessas informações, o portal disponibiliza link direto para outras frentes do $\mathrm{CNPq}$, que se referem à difusão do conhecimento científico de interesse da sociedade em geral.

\subsection{Diretórios}

Os diretórios frequentemente são denominados 'repositórios', "que na verdade são depósitos ou pontos de armazenamento de arquivos ou, mais ainda, locais centrais que estocam e mantêm informações digitais, geralmente dados ou arquivos do computador". (AGUIRRE; CABRERA, 2009 apud SANTOS, 2011, p. 7).

Podem se referir a uma coleção de índices e bases de dados, cujo acesso pode ser gratuito ou ainda listas alfabéticas ou classificadas de nomes, organizações ou assuntos, etc., contendo títulos, endereços, afiliações e outros dados profissionais. Pode ser um tipo de lista organizada por nomes de arquivos, juntamente com as informações que possibilitam que sejam recuperados pelo sistema operacional. (AGUIRRE; CABRERA, 2009 apud SANTOS, 2011; SANTOS; RIBEIRO, 2003 apud SANTOS, 2011).

Um exemplo de diretório que reúne informações que condizem com as definições citadas anteriormente é o Diretório de pesquisadores em Ciência da Informação da Base de Dados Referenciais de Artigos de Periódicos em Ciência da Informação (BRAPCI) (http://www.brapci.ufpr.br/dir-is.php). O projeto do Diretório de Pesquisadores em Ciência da Informação (DiR-IS) tem como objetivo criar um diretório que possibilite a recuperação de informações sobre os autores dos artigos e das obras referenciadas na BRAPCl. A partir de estudos anteriores e informações retiradas da Plataforma Lattes foram coletadas informações para construção do diretório de autores, sobre os quais foram selecionadas as seguintes informações: nome; instituição; endereço; formação; atuação; áreas e subáreas em que atuam a produção científica na BRAPCI. Além do Diretório dos Pesquisadores em Ciência da Informação, a BRAPCI disponibiliza referências e resumos de 7.299 textos publicados em 37

Perspectivas em Gestão \& Conhecimento, João Pessoa, v. 6, n. 2, p. 32-47, jul./dez. 2016 
periódicos nacionais impressos e eletrônicos da área de $\mathrm{Cl}$. Dos periódicos disponíveis 26 estão ativos e 11 estão descontinuados (BRAPCl, 2015).

\subsection{Bases de Dados}

Base de dados é uma coleção de registros normalmente gerenciada por um sistema de busca. As bases de dados variam em seu conteúdo (páginas Web, patentes, dados estatísticos, normas técnicas, periódicos científicos, etc.). (ALVES et al., 2012).

Para Cunha (2001), base de dados é a coleção de dados que serve de suporte a um sistema de recuperação de informações. As bases de dados, reunidas, formam os bancos de dados.

"As bases de dados podem ser impressas e automatizadas, sendo esta última forma mais conhecida como base eletrônica; ou seja, essas informações podem ser apresentadas em CD-ROM, videodisco CD-I (disco compacto interativo) e online". (SANTOS, 2011, p. 6).

As bases de dados possuem os seguintes objetivos e funções: fornecem informação atualizada, precisa e confiável e de acordo com a demanda; promovem visibilidade e acesso à produção de conhecimento; disseminam a produção técnico-científica em âmbito nacional e internacional; permitem a realização de controle bibliográfico da produção de determinada localidade geográfica (região, país) ou em determinado campo do conhecimento. (GONÇALVES; SILVA, 2009).

As bases de dados podem ser: bibliográficas; catalográficas ou referenciais. As bases bibliográficas ou referenciais: incluem referências bibliográficas e resumos. Agrupa e organiza referências de artigos científicos, monografias, teses, trabalhos de congressos e outros documentos convencionais e não convencionais. Estas referências são, normalmente, acompanhadas do resumo, além dos dados que identificam cada artigo ou documento incluído na base de dados, seguindo critérios de seleção próprios. As textuais incluem textos completos de artigos de periódicos, jornais ou outras modalidades de documentos. As catalográficas: representam o acervo de uma biblioteca ou de uma rede de bibliotecas, sem indicação do conteúdo dos documentos. (ALVES et al., 2012).

Como exemplo de bases de dados pode-se citar a Library, Information Science \& Technology Abstracts (LISTA) (https://www.ebscohost.com/academic/library-informationscience-and-technology-abstracts), literatura da área de bibliotecas e administração da informação. Artigos. É um banco de dados disponível gratuitamente para qualquer biblioteca. Possui uma lista de índices com mais de 580 revistas do núcleo, com mais de 50 revistas prioritárias, e 125 revistas seletivas; além de livros e relatórios de investigação, com uma cobertura no banco de dados desde os anos 1960 (LIBRARY, INFORMATION SCIENCE \& TECHNOLOGY ABSTRACTS, 2015).

Outro exemplo é a Biblioteca do Congresso Norte-Americano, a Library of Congress (https://www.loc.gov/), uma base que cobre o acervo documental existente. Sua coleção é de mais de 138 milhões de itens, 32 milhões de livros, materiais impressos em 470 idiomas, 61 milhões de manuscritos, possui a maior coleção de livros raros da América do Norte e do mundo, vasta coleção de materiais legais, filmes, mapas, partituras e gravações sonoras (LIBRARY OF CONGRESS, 2015).

A base de dados Bielefeld Academic Search Engine (BASE) (https://www.basesearch.net/) disponibiliza em acesso aberto artigos completos de autores de diversos países. A BASE foi criada pela Biblioteca da Universidade de Bielefeld desde 2004 e, atualmente, contém uma coleção de 78.751 .918 documentos, oriundos de 3.729 fontes de conteúdo (BIELEFELD ACADEMIC SEARCH ENGINE, 2015).

Perspectivas em Gestão \& Conhecimento, João Pessoa, v. 6, n. 2, p. 32-47, jul./dez. 2016 


\section{CONSIDERAÇÕES FINAIS}

A informação está sempre destinada a um público alvo. Para cada informação, seja ela de cunho científico ou não, existe um usuário de interesse que a utiliza para realizar alguma tarefa, obter conhecimento e tomar decisões.

Poder identificar quais as fontes relevantes, pertinentes e necessárias e aonde buscálas para atender uma demanda informacional, seja para solucionar uma curiosidade ou subsidiar uma pesquisa, se torna essencial para qualquer indivíduo.

Existem fontes e recursos informacionais disponíveis de forma oral, impressa, digital e multimídia, que possuem funções diferentes e se diferenciam por meio do seu conteúdo, que consequentemente se direcionam a usuários específicos.

Por isso, saber onde encontrar fontes de informação, seja em texto, imagem, som, ou multimídia, faz parte integral do exercício da pesquisa científica. Constitui-se em uma tarefa essencial para os pesquisadores, acadêmicos e profissionais da informação, utilizarem fontes qualitativas.

Nessa perspectiva, conhecer fontes confiáveis, especializadas ou não e aplicar critérios de seleção, pode garantir a qualidade da informação a ser recuperada. Tanto no caso da pesquisa científica, como empresarial ou comercial, as informações recuperadas devem ser de qualidade, ter confiabilidade e credibilidade, contribuindo para a excelência no repasse de informação.

Os recursos e instrumentos para localizar as fontes de informação podem ser um caminho para o sucesso dessa busca, pois se constituem em uma ferramenta de seleção, organização, recuperação, acesso, disseminação e uso da informação.

Destaca-se que a atualização constante das fontes de informação é necessária, devido à velocidade com que as informações se alteram e os sistemas se modificam da mesma maneira, pois necessitam se atualizar para promover o acesso aos registros de forma segura e confiável. Dessa forma, conhecer os instrumentos para recuperar as diversas fontes de informação disponíveis é um elemento-chave para o sucesso na busca de informações.

\section{REFERÊNCIAS}

ALVES, M. B. M. et al. Fontes de informação online: nível básico. Florianópolis, 2012. 24 slides, color. Disponível em: http://www.bu.ufsc.br/design/pptOficialNivelBasico.pdf. Acesso em: 05 set. 2015.

ANDRADE, Maria Margarida de. Introdução à metodologia do trabalho científico: elaboração de trabalhos na graduação. 6. ed. São Paulo: Atlas, 2003.

ARXIV.ORG. Disponível em: http://arxiv.org/. Acesso em: 04 set. 2015.

BIELEFELD ACADEMIC SEARCH ENGINE. BASE. Disponível em: https://www.base-search.net/. Acesso em: 02 out. 2015.

BIREME. Guia 2001 de desenvolvimento da Biblioteca Virtual em Saúde. São Paulo, 2001. Disponível em: http://webcache.googleusercontent.com/search?q=cache:9HMvJX99nQoJ :www.bireme.br/bvs/reuniao/doc/guiabvs2001.doc $\& \mathrm{~cd}=1 \& \mathrm{hl}=\mathrm{pt}-\mathrm{BR} \& \mathrm{ct}=\mathrm{clnk} \& \mathrm{gl}=\mathrm{br}$. Acesso em: 7 set. 2015.

BRAPCI. Base de dados referenciais de artigos de periódicos em ciência da informação. Disponível em: http://www.brapci.ufpr.br/ic.php?dd99=about. Acesso em: 27 jul. 2015.

CAMARGO, L. S. de A. de; VIDOTTI, S. A. B. C. Arquitetura da informação para repositórios científicos digitais. In: SAYÃO, Luíz Fernando et al. (Orgs.). Implantação e gestão de

Perspectivas em Gestão \& Conhecimento, João Pessoa, v. 6, n. 2, p. 32-47, jul./dez. 2016 
repositórios institucionais: políticas, memória, livre acesso e preservação. Salvador: EDUFBA, 2009.

CAMPELLO, B. S.; CENDÓN, B. V.; KREMER, J. M. (Orgs.). Fontes de informação para pesquisadores e profissionais. Belo Horizonte: Ed. UFMG, 2000.

CERVO, Amado Luiz; BERVIAN, Pedro Alcino. Metodologia científica. 5. ed. São Paulo: Pearson Prentice Hall, 2002.

CONSELHO NACIONAL DE DESENVOLVIMENTO CIENTÍFICO E TECNOLÓGICO. Popularização da Ciência. 2015. Disponível em: http://cnpq.br/popularizacao-da-ciencia. Acesso em: 20 nov. 2015.

COSTA, S. Abordagens, estratégias e ferramentas para o acesso aberto via periódicos e repositórios institucionais em instituições acadêmicas brasileiras. Liinc em Revista, Rio de Janeiro, v.4, n.2, p. 218-232, set. 2008. Disponível em: http://repositorio.unb.br/handle/10482/16048. Acesso em: 28 nov. 2015.

CUNHA, Murilo Bastos da. Biblioteca digital: bibliografia das principais fontes de informação. Ciência da Informação, Brasília, DF, v. 39, n. 1, p.88-107, jan./abr. 2010.

Lemos, 2001.

Para saber mais: fontes de informação em ciência e tecnologia. Brasília: Briquet de DICIONÁRIO BRASILEIRO DE TERMINOLOGIA ARQUIVÍSTICA. Rio de Janeiro: Arquivo Nacional, 2005. (Publicações Técnicas; № 51)

E-LIS. EPrints in Library and Information Science. Disponível em: http://eprints.rclis.org/. Acesso em: 04 set.2015.

EPRINTS. Self-Archiving FAQ. Disponível em: http://www.eprints.org/openaccess/selffaq/\#What-is-Eprint. Acesso em: 30 set. 2015.

EPRINTS SOTON. Disponível em: http://library.soton.ac.uk/openaccess/introduction. Acesso em: 04 set. 2015.

FERREIRA, M. Introdução à preservação digital: conceitos, estratégias e actuais consensos. Universidade do Minho: Escola de Engenharia, 2006. Disponível em: http://eprints.rclis.org/archive/00007977/01/livro.pdf. Acesso em: 4 ago. 2007.

FUJITA, M. S. L. (Org.). A indexação de livros: a percepção de catalogadores e usuários de bibliotecas universitárias. São Paulo: Cultura Acadêmica, 2009.

GARRIDO, I. dos S.; ROGRIGUES, R. S. Portais de periódicos científicos online: organização institucional das publicações. Perspectivas em Ciência da Informação, v. 15, n. 2, p. 56-72, maio./ago. 2010.2 Disponível em: http://portaldeperiodicos.eci.ufmg.br/index.php/pci/article/viewFile/943/732. Acesso em: 21 ago. 2015.

GIL, Antônio Carlos. Como elaborar projetos de pesquisa. 4. ed. São Paulo: Atlas, 2002.

GOMES, M. J.; ROSA, F. Apresentação. In: GOMES, M. J.; ROSA, F. Repositórios institucionais: democratizando o acesso ao conhecimento. Salvador: EDUFBA, 2010. p. 7-9.

GONÇALVES, L. O.; SILVA, R. N. C. da. Bases de dados referenciais bibliográficos e catalográficos. Atividade referente à disciplina CBD0201: Recursos Informacionais II, do Centro de Biblioteconomia e Documentação da Escola de Comunicações e Artes da Universidade de São Paulo. 2009. Disponível em: http://nexus.futuro.usp.br/atividades/1102/file1.ppt. Acesso 
em: 18 ago. 2015.

GUÉDON, Jean-Claude. It's a Repository, It's a Depository, It's an Archive...: open access, digital collections and value. Arbor Ciencia, Pensamiento y Cultura, CLXXXV, n. 737, p. 581-595, maio/jun. $2009 . \quad$ Disponível em: arbor.revistas.csic.es/index.php/arbor/article/download/315/316. Acesso em: 04 ago. 2015.

HJØRLAND, B.; ANDERSEN, J.; SØNDERGAARD, T. F. UNISIST model and knowledge domains. In: ENCYCLOPEDIA OF LIBRARY AND INFORMATION SCIENCE: First Update Supplement. New York: CRC Press LLC, $2005 . \quad$ p. 129 - 135. Disponível em: http://iva.ku.dk/ansatte/?pure=files\%2F47044534\%2FUNISIST model and knowledge domai ns.pdf. Acesso em: 20 nov. 2015.

IFLA. More about IFLA: who we are. 17 mar. 2015. Disponível em: <http://www.ifla.org/>. Acesso em: 04 set. 2015.

IFLA MEETINGS OF EXPERTS ON AN INTERNATIONAL CATALOGUING CODE. Statement of International Cataloguing Principles. 2009. Disponível em: http://www.ifla.org/en/publications/statement-of-international-cataloguing-principles.

Acesso em: 08 set. 2015.

INSTITUTO BRASILEIRO DE INFORMAÇÃO EM CIÊNCIA E TECNOLOGIA (IBICT). RI: repositórios institucionais: boas práticas para a construção de repositórios institucionais da produção científica. Brasília: $\quad$ IBICT, 2012.2 Disponível em: http://livroaberto.ibict.br/bitstream/1/703/1/BoasprAticasparaconstruCAorepositoriosinstituc ionaisdaproduCAocientifica.pdf. Acesso em: 04 set. 2015.

. Sobre repositórios digitais. Disponível em: http://www.ibict.br/informacao-paraciencia-tecnologia-e-inovacao\%20/repositorios-digitais/sobre-repositorios-digitais.

Acesso em: 07 set. 2015.

KURAMOTO, H. Estatísticas sobre Repositórios no Brasil. Blog do Kuramoto, 30 out.2012. Disponível em: http://kuramoto.blog.br/2012/10/30/estatisticas-sobre-ri-no-brasil/. Acesso em: 29 nov. 2015.

LE COADIC, Yves-François. A ciência da informação. Brasília: Briquet de Lemos, 1996.

LIBRARY, INFORMATION SCIENCE \& TECHNOLOGY ABSTRACTS (LISTA). Disponível em: https://www.ebscohost.com/academic/library-information-science-and-technology-abstracts. Acesso em: 04 set.2015.

LIBRARY OF CONGRESS. Disponível em: https://www.loc.gov/. Acesso em: 04 set.2015.

LYNCH, C. A. Institutional Repositories: essential infrastructure for scholarship in the Digital Age. ARL, n. 226, p. 1-7, Feb. 2003. Disponível em: http://www.arl.org/resources/pubs/br/br226/br226ir.shtml. Acesso em: 2 nov. 2015.

MARTINHO, N. O.; FUJITA, M. S. L. La catalogación de matérias: apuntes históricos sobre su normalización. Scire, Zaragoza, v. 16, p. 61-70, 2010.

MEY, E. S. A.; SILVEIRA, N. C. Catalogação no plural. Brasília: Briquet de Lemos, 2009.

MICHAELIS. Dicionário de Português Online. Conceito de repositório. Disponível em: http://michaelis.uol.com.br/moderno/portugues/index.php?lingua=portuguesportugues\&palavra=reposit\%F3rio. Acesso em: 07 set. 2015.

$$
\text { Significado de bibliografia. Disponível }
$$

em: $\overline{\mathrm{http}: / / m i c h a e l i s . u o l . c o m} . \mathrm{br} / \mathrm{moderno} /$ portugues/index.php?lingua=portugues- 
portugues\&palavra=bibliografia. Acesso em: 29 out. 2015.

MONTEIRO, F.; BRASCHER, M. Organização da informação em repositórios temáticos: o uso da modelagem conceitual. In: ENCONTRO NACIONAL DE PESQUISA EM CIÊNCIA DA INFORMAÇÃO, 8., 2007, Salvador. Anais... Salvador, 2007.

MURAKAMI, T. R. M.; FAUSTO, S. Panorama atual dos Repositórios Institucionais das Instituições de Ensino Superior no Brasil. Incid, São Paulo, v. 4, n. 2, p.185-201, set. 2013. Disponível em: http://www.revistas.usp.br/incid/article/view/69327. Acesso em: 05 ago. 2015.

OLIVEIRA, C. C. de. A interação dos usuários da UFMG com o catálogo online do sistema Pergamum. 2008. 199 f. Dissertação (Mestrado em Ciência da Informação) - Universidade Federal de Minas Gerais, Escola de Ciência da Informação, Belo Horizonte, 2008. Disponível em: http://www.bibliotecadigital.ufmg.br/dspace/handle/1843/EARM- 7H2Q4E. Acesso em: 18 out. 2010.

PAIVA, R. O. de. Online public access catalogs: um estudo dos catálogos online. In: XIV ENCONTRO REGIONAL DE ESTUDANTES DE BIBLIOTECONOMIA, DOCUMENTAÇÃO, CIÊNCIA DA INFORMAÇÃO E GESTÃO DA INFORMAÇÃO, Os novos campos da profissão da informação na contemporaneidade, 16 a 22 de janeiro de 2011. Disponível em: http://rabci.org/rabci/sites/default/files/ON-

LINE\%20PUBLIC\%20ACCESS\%20CATALOGS\%20um\%20estudo\%20dos\%20cat\%C3\%A1logos\%20 on-line.pdf. Acesso em: 20 nov. 2015.

PINHEIRO, L. V. R. Fontes ou recursos de informação: categorias e evolução conceitual. Pesquisa Brasileira em Ciência da Informação e Biblioteconomia, Rio de Janeiro, IBICT, v. 1, n. 1, 2006.2 Disponível em: http://periodicos.ufpb.br/ojs/index.php/pbcib/article/view/8809/4716. Acesso em: 20 nov. 2015.

POZZI, B. Do catálogo impresso ao online: alguns desafios para os profissionais bibliotecários. Dez. $2011 . \quad$ Disponível em: http://projetoinformaacaoecultura.blogspot.com.br/2011/12/palestra-do-catalogo-impressoao-online.html. Acesso em: 20 nov. 2015.

RODRIGUES, A. M. F. Repositórios institucionais de acesso livre: estudo de produção e uso. 2011. 183f. Dissertação (Mestrado) - Curso de Ciência da Informação, Universidade do Porto, Porto, 2011. Disponível em: http://repositorio-aberto.up.pt/bistream/10216/61655/1 1000148784.pdf. Acesso em: 20 nov. 2015.

SANTOS, G. C. Fontes para indexação para periódicos científicos: um guia para bibliotecários e editores. Campinas, SP: E-Color, 2011. (Manuais Técnicos BFE, n. 6).

SARMENTO, F. et al. Algumas considerações sobre as principais declarações que suportam o movimento acesso livre. 2005. Disponível em: http://eprints.rclis.org/8512/. Acesso em: 30 nov. 2015.

SCHOLARLY ELECTRONIC PUBLISHING BIBLIOGRAPHY. Charles W. Bailey, Jr. Version 80: 10/30/2011. 15th Year of Publication. Disponivel em: http://www.digitalscholarship.org/sepb/sepb.html. Acesso em 04 set. 2015.

SENAC-SP. Portal de Divulgação Científica do Senac/SP. Disponível em: http://www.sp.senac.br/. Acesso em: 04 set. 2015.

SILVEIRA, A. da. A usabilidade em catálogos online. 2003. 63 f. Trabalho de Conclusão de 
Curso (Graduação) - Universidade do Rio de Janeiro, Rio de Janeiro, RJ, 2003. Disponível em: http://rabci.org/rabci/sites/default/files/bi132.pdf. Acesso em: 25 out. 2010.

UFSCar. Qual a diferença entre o Portal de Teses da Capes e as BDTDs do IBICT? 2011. Disponível em: http://www.seabd.bco.ufscar.br/referencia/qual-diferenca-entre-portal-tesescapes-bdtds-ibict. Acesso em: 04 set. 2015.

Artigo recebido em 10/12/2015 e aceito para publicação em 17/06/2016 